\title{
Preemptive analgesic effectiveness of oral ketorolac plus local tramadol after impacted mandibular third molar surgery
}

\author{
Mario A. Isiordia-Espinoza ${ }^{1}$, Amaury J. Pozos-Guillén ${ }^{2}$, Ricardo Martínez-Rider ${ }^{3}$, Jorge E. Herrera-Abarca ${ }^{4}$, \\ José Pérez-Urizar ${ }^{5}$
}

\author{
${ }^{1}$ DDS, MS Sección de Estudios de Posgrado e Investigación, Escuela Superior de Medicina, Instituto Politécnico Nacional, D.F., \\ México \\ ${ }^{2}$ DDS, PhD Departamento de Cirugía Oral y Maxilofacial, Facultad de Estomatología, Universidad Autónoma de San Luis Po- \\ tosí, San Luis Potosí, México \\ ${ }^{3}$ DDS, Departamento de Cirugía Oral y Maxilofacial, Facultad de Estomatología, Universidad Autónoma de San Luis Potosí, \\ San Luis Potosí, México \\ ${ }^{4} \mathrm{PhD}$, Clínica de Enfermedades Crónicas y De Procedimientos Especiales S.C., Morelia, México \\ ${ }^{5} \mathrm{PhD}$, Departamento de Farmacología, Facultad de Ciencias Químicas, Universidad Autónoma de San Luis Potosí, San Luis \\ Potosí, México
}

Correspondence:

Facultad de Estomatología

Universidad Autónoma de San Luis Potosí

Av. Dr. Manuel Nava \#2, Zona Universitaria

C.P. 78290; San Luis Potosí, S.L.P. México

apozos@uaslp.mx

\begin{abstract}
Isiordia-Espinoza MA, Pozos-Guillén AJ, Martínez-Rider R, HerreraAbarca JE, Pérez-Urizar J. Preemptive analgesic effectiveness of oral ketorolac plus local tramadol after impacted mandibular third molar surgery. Med Oral Patol Oral Cir Bucal. 2011 Sep 1;16 (6):e776-80. http://www.medicinaoral.com/medoralfree01/v16i6/medoralv16i6p776.pdf
\end{abstract}

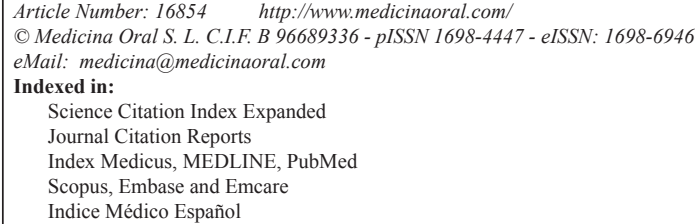

\begin{abstract}
Objective: The aim of this study was to compare preemptive analgesia of oral ketorolac plus submucous local placebo with oral ketorolac plus submucous local tramadol after impacted mandibular third molar surgery.

Study design: A double-blind, randomized, placebo-controlled clinical trial was conducted. Patients were randomized into two treatment groups ( $\mathrm{n}=15$ per group): group $\mathrm{A}$, oral ketorolac $10 \mathrm{mg}, 30$ minutes before surgery plus submucous local placebo ( $1 \mathrm{~mL}$ saline solution); group B, oral ketorolac $10 \mathrm{mg}, 30$ minutes before surgery plus submucous local tramadol (50 mg diluted in $1 \mathrm{~mL}$ saline solution). We evaluated the intensity of pain, time for the first analgesic rescue medication, and total analgesic consumption.

Results: Pain intensity, number of patients requiring analgesic rescue medication, number of patients in each group not requiring analgesic rescue medication, and total analgesic consumption showed statistical significance.

Conclusions: Preemptive use of oral ketorolac plus submucous local tramadol is an alternative treatment for acute pain after surgical removal of an impacted mandibular third molar.
\end{abstract}

Key words: Preemptive analgesia, ketorolac, tramadol, third molar. 


\section{Introduction}

Third molar surgery is the most common procedure carried out by oral and maxillofacial surgeons, and it is a common model for evaluating the efficacy of analgesics for acute dental pain relief (1). Pain associated with surgical removal of mandibular third molars ranges between moderate and severe during the first 24 hours (h) after surgery, with pain peaking between 6 and $8 \mathrm{~h}$ when a conventional local anesthetic is used (2). It has been suggested that preemptive analgesia is an alternative for treating the postsurgical pain associated with third molar removal (3).

Various analgesics have been used for this purpose, including nonsteriodal anti-inflammatory drugs (NSAIDs) and some opioids $(4,5)$. Ketorolac is an NSAID that has been shown to be effective after oral and parenteral administration. As with other NSAIDs, ketorolac produces its effect through the inhibition of prostaglandin synthesis, the fatty acid that promotes pain. Because of its efficacy and high potency, additional mechanisms of action have been proposed, including a modulator effect on opioid receptors and stimulation of nitric oxide release (6).

Tramadol is an opioid analgesic (OA) that is clinically effective in treating moderate to severe pain; it has a low addiction potential. It is used against multiple acute pain conditions, including postsurgical pain. It acts on opioid receptors and seems to modify the transmission of pain, inhibiting the reuptake of monoamines (7). Previously, we reported that local submucous tramadol administration is effective in reducing pain after impacted mandibular third molar removal (8), as well as prolonging the time of local anesthesia produced by articaine (9). The objective of this study was to compare the preemptive analgesia of oral ketorolac plus submucous (s.m.) local placebo with oral ketorolac plus s.m. local tramadol after impacted mandibular third molar surgery. Our hypothesis is that oral ketorolac plus s.m. local tramadol administered preoperatively produces a superior postoperative analgesic effect compared with oral ketorolac plus s.m. local placebo.

\section{Materials and Methods}

This study was a double-blind, randomized, placebocontrolled clinical trial conducted in accordance with the Declaration of Helsinki. The Ethics Committee of the Faculty of Dentistry at San Luis Potosí University, Mexico, approved this study. All subjects were informed of the possible risks of oral surgery and treatments used. Each patient accepted and signed an informed consent form.

The sample size was calculated as 15 patients in each group with a type I error of 0.05 and statistical power of $80 \%$, using as response variable the first analgesic rescue medication for postoperative pain. One hundred and twenty minutes (min.) was considered a significant clinical difference, with an estimated mean SD of 113 min. obtained in a previous study that evaluated the efficacy of tramadol administered in a combination of routes for reducing pain after removal of an impacted mandibular third molar (7). Accordingly, we obtained a total of 13 patients but, allowing for a possible loss of $10 \%$ in each group, 15 patients were included. Our reasoning was that this number of patients was considered acceptable to demonstrate significant differences attributable to the experimental therapy used.

Inclusion criteria were as follows: age 18 to 25 years, either gender, free of systemic disease, clinical and radiographic diagnosis of an impacted mandibular third molar, no pain associated with the subject third molar up to the day of the surgery, and grade II or III difficulty of extraction. Exclusion criteria included the use of analgesics $24 \mathrm{~h}$ before the procedure, history of seizure disorder, pregnancy or lactation, oral contraceptive use, known hypersensitivity to the study medications.

Patients were randomized into two treatment groups, each with 15 patients, using a series of random numbers: Group A, oral ketorolac $10 \mathrm{mg}, 30 \mathrm{~min}$. before surgery plus s.m. local placebo (1 millilitre $(\mathrm{ml})$ saline solution); Group B, oral ketorolac $10 \mathrm{mg}$ plus s.m. local tramadol $50 \mathrm{mg}$ diluted in $1 \mathrm{ml}$ saline solution.

All surgical procedures were carried out in the Department of Oral and Maxillofacial Surgery by the same surgeon, and evaluations were carried out by an independent investigator. Anesthesia was by nerve block of the lingual, buccal, and inferior alveolar nerves using two 1.8-mL capsules of $4 \%$ articaine containing 1:100,000 epinephrine (Medicaine, Septodont, France), after tramadol or a placebo were administered in the same area using an insulin syringe. Once anesthesia was obtained, surgery was started. A mucoperiosteal flap was prepared by making an incision distal to the lower second molar along the anterior edge of the ascending ramus of the mandible. This flap was used to close the surgical wound. Suturing was done with 4-0 silk. Difficulty of extraction was based on a modified scale of Parant, as follows: Grade I, extraction with forceps and elevators; Grade II, extraction by osteotomy; Grade III, extraction by osteotomy and coronal section; Grade IV, extraction by osteotomy, root and coronal section; Grade V, complex extraction; Grade Vl, extraction with special techniques. In all cases, duration of the operation (from incision to final suture) was recorded. In each patient, a partial bony impacted mandibular third molar was extracted.

A $100-\mathrm{mm}$ visual analog scale (VAS) was used to assess pain. The VAS consisted of an interval scale ranging from 0 , representing no pain or discomfort, to 100 , representing maximum pain or discomfort. The VAS report was recorded each hour for $12 \mathrm{~h}$ after comple- 
tion of surgery, and a last evaluation was done at $24 \mathrm{~h}$ postsurgery. Patients were given four oral ketorolac 10 $\mathrm{mg}$ pills and were instructed to take one pill for rescue analgesic medication at least 6 hours apart, according to their requirements. An evaluation format was given to each patient to document the time of taking the first ketorolac after the surgery. At the end of the evaluation period $(24 \mathrm{~h})$, the patients returned the unused ketorolac. The pills were counted (also those patients in each group not needing any pills) to determine the number of consumed pills.

Those patients having no pain relief $30 \mathrm{~min}$. after taking oral ketorolac $10 \mathrm{mg}$ were given Ketorolac $30 \mathrm{mg}$ sublingual as a rescue analgesic. Patients were contacted by telephone the evening of the surgery to assess the incidence of adverse events or symptoms, either from medications or surgical complications; they returned to the clinic after 1 week for suture removal. Both patients and the independent evaluator were blinded regarding the administered treatment.

Qualitative variable data are expressed as percentages or proportions. The Fisher exact test was used for statistical analysis of nominal variables, and the MannWhitney U test was employed for ordinal variables. For quantitative variables, the data are shown as means and standard deviations. If the variable presented a normal distribution, the Student $\mathrm{t}$ test was utilized; when this requirement was not met, the Mann-Whitney $U$ test was used. We carried out time-event curves to indicate the percentage of patients in each group not taking analgesics. These percentages were compared using the Log-Rank test. For all tests, a difference was considered significant if the probability that it occurred by chance alone was less than $5 \%(\mathrm{P}<0.05)$.

Table 1. Demographic and surgical variables.

\begin{tabular}{|l|c|c|c|}
\hline \multicolumn{1}{|c|}{ Variable } & $\begin{array}{c}\text { Group A } \\
(\mathbf{n}=15)\end{array}$ & $\begin{array}{c}\text { Group B } \\
(\mathbf{n}=15)\end{array}$ & $\begin{array}{c}\mathbf{P} \\
\text { Value }\end{array}$ \\
\hline Gender (male / female) & $11 / 4$ & $9 / 6$ & .69 \\
\hline Age (mean \pm SD) & $20 \pm 1$ & $20.33 \pm 1$ & .54 \\
\hline Weight (mean \pm SD) & $60.86 \pm 9$ & $57 \pm 9$ & .28 \\
\hline Duration of operation* (mean \pm SD) & $5 \pm 1$ & $6 \pm 1$ & .12 \\
\hline Surgical difficulty ${ }^{\dagger}$ (Grade II / Grade III) & $10 / 5$ & $13 / 2$ & .20 \\
\hline
\end{tabular}

Group A = Oral ketorolac plus s.m. local placebo; Group B = Oral ketorolac plus s.m. local tramadol; $\mathrm{SD}=$ Standard deviation.

* Duration of operation is expressed in minutes.

$\uparrow$ Surgical difficulty: Grade II = Extraction by osteotomy; Grade $\mathrm{III}=$ Extraction by osteotomy and coronal section.

\section{Results}

Demographic characteristics and variables describing the difficulty of surgery were similar among the groups (Table 1).

(Fig. 1) shows the pain intensity evaluated with the VAS. The time for the first rescue analgesic medication postsurgery was not significantly statistically different $(\mathrm{P}>$ $.05)$, but the number of patients who took ketorolac 10 mg orally as the first rescue analgesic was significantly less in group $\mathrm{B}(\mathrm{P}<.05)$. The number in each group not requiring any rescue analgesic medication during the period of evaluation (24 h) showed a statistically significant difference $(\mathrm{P}<0.05)$ (Table 2$)$.

Patients taking rescue analgesic medication throughout the $12 \mathrm{~h}$ are shown on the time-event curve in (Fig. 2). The curves show the time at which each patient consumed the first rescue analgesic medication and the percentage of patients in each group who had not received any rescue analgesic $(\mathrm{P}<0.05)$. The end of each curve indicates the proportion of patients in each group who did not take the first rescue analgesic medication during the first $12 \mathrm{~h}$ after surgery $(\mathrm{P}<0.05)$.

Total analgesic consumption for group A was significantly great than that of group $\mathrm{B}(\mathrm{P}<0.05)$. During the evaluation period, two group A patients required rescue

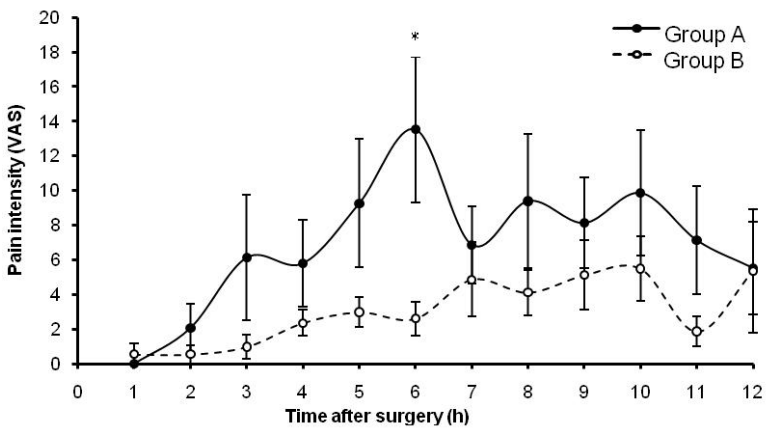

Fig. 1. Pain intensity means during first 12 hours postsurgery $(* \mathrm{P}<0.05)$.

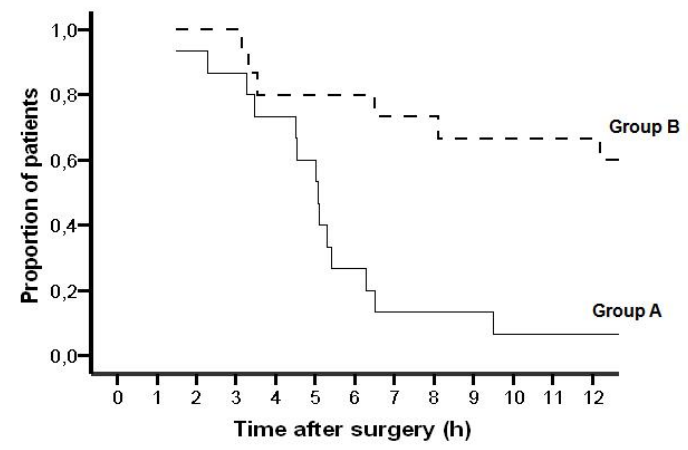

Fig. 2. Time-event curves of the first $12 \mathrm{~h}$ postsurgery. 
Table 2. Variables evaluated as indicators of analgesic efficacy.

\begin{tabular}{|l|c|c|c|}
\hline \multicolumn{1}{|c|}{ Variable } & $\begin{array}{c}\text { Group A } \\
(\mathbf{n = 1 5})\end{array}$ & $\begin{array}{c}\text { Group B } \\
(\mathbf{n}=\mathbf{1 5})\end{array}$ & P Value \\
\hline $\begin{array}{l}\text { Time of first rescue analgesic } \\
\text { medication, minutes (Mean } \pm \text { SD) }\end{array}$ & $\begin{array}{c}307.9 \pm \\
119\end{array}$ & $308 \pm 134$ & .93 \\
\hline $\begin{array}{l}\text { Number (\%) of patients who } \\
\text { consumed the first rescue analgesic } \\
\text { medication during the period of } \\
\text { evaluation (12 h) }\end{array}$ & $\begin{array}{l}14 \\
(93.33)\end{array}$ & $5(33.33)$ & .001 \\
\hline $\begin{array}{l}\text { Number (\%) of patients requiring no } \\
\text { rescue analgesic medication during } \\
\text { the period of evaluation }(24 \text { h) }\end{array}$ & $1(6.67)$ & $7(46.66)$ & .03 \\
\hline $\begin{array}{l}\text { Total analgesic consumption during } \\
24 \text { hours (Mean } \pm \text { SD) }\end{array}$ & $3 \pm 1$ & $1.8 \pm 2$ & .04 \\
\hline $\begin{array}{l}\text { Number (\%) of patients requiring } \\
\text { rescue analgesic medication (12 h) }\end{array}$ & $2(13.33)$ & $1(6.67)$ & .88 \\
\hline
\end{tabular}

Group A = Oral ketorolac plus s.m. local placebo; Group B = Oral ketorolac plus s.m. local tramadol; $\mathrm{SD}=$ Standard deviation.

medication with sublingual ketorolac $30 \mathrm{mg}$ compared with one group B patient (Table 2). There were no complications associated with the surgical procedure itself, and no patients reported adverse events associated with the medications.

\section{Discussion}

This study demonstrated that oral administration of 10 $\mathrm{mg}$ ketorolac plus $50 \mathrm{mg}$ of tramadol administered s.m. showed clear differences in the need for postoperative analgesic consumption compared with the group receiving $10 \mathrm{mg}$ oral ketorolac plus a local placebo s.m. We found that only 1 patient in group A needed no pain medication within $12 \mathrm{~h}$ after surgery compared with 10 patients from group B. We found statistically significant differences between groups in pain intensity measured by VAS at $6 \mathrm{~h}$ postsurgery. However, it seems that this difference evaluated by itself does not have clinical significance for pain relief because of its subjective assessment; however, we consider the clear difference in analgesic consumption after treatment to be clinically relevant.

The topic of preemptive analgesia is controversial; there have been reports in favor as well those against. For this reason, some guidelines have been developed to assess the quality of reports of randomized clinical trials in pain research. It has been reported that blind assessments produce significantly lower and more consistent scores than do open assessments (10). Furthermore, a meta-analysis by Ong et al. (11) assessing the ability of preemptive analgesic interventions to attenuate postoperative pain scores, decrease postoperative analgesic requirements, and prolong the time to first rescue analgesia demonstrated an overall beneficial effect in selected analgesic regimens that was most pronounced after epidural analgesia, local wound infiltrations, and systemic NSAID administration. This meta-analysis also showed many deficiencies in the design of randomized clinical trials in the field of oral surgery.

Pre- or postoperative administration of $550 \mathrm{mg}$ naproxen or $1,000 \mathrm{mg}$ diflunisal orally produces good pain relief after surgical removal of impacted third molars. However, no significant differences were found in either study about pain relief between the pre- and postoperative approaches $(12,13)$. A study using preemptive analgesia showed that tramadol $50 \mathrm{mg}$ intravenous (i.v.) is more effective than oral tramadol $50 \mathrm{mg}$ in relieving pain after third molar surgery (14). Another study demonstrated that ketorolac $30 \mathrm{mg}$ i.v. produces better preventive analgesic efficacy than tramadol $50 \mathrm{mg}$ i.v. when administered preoperatively in third molar surgery (15).

One approach to overcoming these therapeutic limitations is to maximize drug levels at the site of action and minimize systemic exposure by administering the drug directly to the site of tissue injury. Local application of aspirin and acetaminophen at subtherapeutic doses (50 $\mathrm{mg}$ ) has been shown to produce analgesia superior to 
the placebo (16). An aspirin solution applied topically in the oral cavity has an analgesic effect on experimental and clinical pain, which appears to be mediated locally and not by systemic absorption (17). Ketoprofen $10 \mathrm{mg}$ administered into the two mandibular extraction sites showed better analgesic efficacy than a $25-\mathrm{mg}$ ketoprofen oral capsule. In addition, plasma concentrations of 10 -mg ketoprofen were lower than the 25 -mg oral capsule of ketoprofen (18).

We believe that the local administration of analgesics may also be an acceptable alternative to the use of NSAIDs in the oral cavity, particularly in patients with increased risk of gastrointestinal bleeding after enteral administration $(19,20)$. On the other hand, reduction in plasma concentration of any NSAID is desirable owing to alterations in renal function associated with the ingestion of these drugs, which are estimated to occur in approximately $1 \%$ of exposed patients (21).

The main finding of this study is that, in patients undergoing removal of an impacted mandibular third molar, treatment with preemptive ketorolac plus s.m. local tramadol resulted in an important reduction in consumption of postoperative analgesics. This study suggests that the use of ketorolac, along with s.m. local tramadol in a regimen of preemptive analgesia, represents an alternative for the treatment of acute pain after removal of an impacted mandibular third molar.

\section{References References with links to Crossref-DOI}

1. Cooper SA, Beaver WT. A model to evaluate mild analgesics in oral surgery outpatients. Clin Pharmacol Ther. 1976;20:241-50.

2. Seymour RA, Meechan JG, Blair GS. An investigation into postoperative pain after third molar surgery under local analgesia. Br J Oral Maxillofac Surg. 1985;23:410-8.

3. Ong CK, Seymour RA. Pathogenesis of postoperative oral surgical pain. Anesth Prog. 2003;50:5-17.

4. López Carriches C, Martínez González JM, Donado Rodríguez $M$. The use of methylprednisolone versus diclofenac in the treatment of inflammation and trismus after surgical removal of lower third molars. Med Oral Patol Oral Cir Bucal. 2006;11:E440-5.

5. Esteller-Martínez V, Paredes-García J, Valmaseda-Castellón E, Berini-Aytés L, Gay-Escoda C. Analgesic efficacy of diclofenac sodium versus ibuprofen following surgical extraction of impacted lower third molars. Med Oral Patol Oral Cir Bucal. 2004;9:448-53; 444-8.

6. Pérez-Urizar J, Granados-Soto V, Castañeda-Hernández G, Hong E, González C, Martínez JL, et al. Analgesic efficacy and bioavailability of ketorolac in postoperative pain: a probability analysis. Arch Med Res. 2000;31:191-6.

7. Scott LJ, Perry CM. Tramadol: a review of its use in perioperative pain. Drugs. 2000;60:139-76.

8. Pozos AJ, Martínez R, Aguirre P, Pérez J. Tramadol administered in a combination of routes for reducing pain after removal of an impacted mandibular third molar. J Oral Maxillofac Surg. 2007;65:1633-9.

9. Pozos AJ, Martinez R, Aguirre P, Perez J. The effects of tramadol added to articaine on anesthesia duration. Oral Surg Oral Med Oral Pathol Oral Radiol Endod. 2006;102:614-7.

10. Jadad AR, Moore RA, Carroll D, Jenkinson C, Reynolds DJ, Gavaghan DJ, et al. Assessing the quality of reports of randomized clinical trials: is blinding necessary? Control Clin Trials. 1996;17:112.
11. Ong CK, Lirk P, Seymour RA, Jenkins BJ. The efficacy of preemptive analgesia for acute postoperative pain management: a meta-analysis. Anesth Analg. 2005;100:757-73.

12. Sisk AL, Grover BJ. A comparison of preoperative and postoperative naproxen sodium for suppression of postoperative pain. J Oral Maxillofac Surg. 1990;48:674-8.

13. Sisk AL, Mosley RO, Martin RP. Comparison of preoperative and postoperative diflunisal for suppression of postoperative pain. J Oral Maxillofac Surg. 1989;47:464-8.

14. Ong CK, Lirk P, Tan JM, Sow BW. The analgesic efficacy of intravenous versus oral tramadol for preventing postoperative pain after third molar surgery. J Oral Maxillofac Surg. 2005;63:1162-8.

15. Ong KS, Tan JM. Preoperative intravenous tramadol versus ketorolac for preventing postoperative pain after third molar surgery. Int J Oral Maxillofac Surg. 2004;33:274-8.

16. Moore UJ, Seymour RA, Rawlins MD. The efficacy of locally applied aspirin and acetaminophen in postoperative pain after third molar surgery. Clin Pharmacol Ther. 1992;52:292-6.

17. Loch WE, Wenger AP, Loch MH, Loch WE, Reiriz HM. Local aspirin analgesia in the oral cavity. Clin Pharmacol Ther. 1983;33:642-8

18. Dionne RA, Gordon SM, Tahara M, Rowan J, Troullos E. Analgesic efficacy and pharmacokinetics of ketoprofen administered into a surgical site. J Clin Pharmacol. 1999;39:131-8.

19. Gabriel SE, Jaakkimainen L, Bombardier C. Risk for serious gastrointestinal complications related to use of nonsteroidal anti-inflammatory drugs. A meta-analysis. Ann Intern Med. 1991;115:787-96.

20. Laporte JR, Carné X, Vidal X, Moreno V, Juan J. Upper gastrointestinal bleeding in relation to previous use of analgesics and non-steroidal anti-inflammatory drugs. Catalan Countries Study on Upper Gastrointestinal Bleeding. Lancet. 1991;337:85-9.

21. Whelton A, Hamilton CW. Nonsteroidal anti-inflammatory drugs: effects on kidney function. J Clin Pharmacol. 1991;31:588-98.

\section{Acknowledments}

Mario Alberto Isiordia Espinoza was a Fellow-IPN. Special thanks to Victor Fierro, and Alicia Torres for their time and effort in assisting this study. We would like to thank Norman Wahl, for his assistance in editing this manuscript. 